\title{
دراسة عناصر القصة لرواية حبيي داعشي لهاجر عبدالصمد
}

مسعود باوانبوري

طالب الدكتوراه في قسم اللغة العببية و آداهما بجامعة الشهيد مدني بأذربيجان

masoudbavanpouri@yahoo.com
طيبة فتحي ايرانشاهي

طالبة الدكتوراه في قسم اللغة العربية و آدابها بجامعة لرستان

fathi.ta@fh.iu.ac.ir
*الدكتور سيد محمود ميرزايي الحسيني

أستاذ مشارك في قسم اللغة العربية و آدابها بجامعة لرستان mirzaei.m@lu.ac.ir

الملخص

وقد تمكن مؤلفو كل فترة، من خلال التعبير عن آرائهم وكتاباتم، بعرض مشاكل الجُتمع بشكل الوواية. هاجر عبدالصمد من رواة القصص المعاصرين العراقيين. حبيبي داعشي هي روايتها الأولى. تكتشف الكاتبة فيها عن الإبادة الجماعية وجرائم داعش وتروي قصة الفتيات اللواتي، مع الإحباط من قسوة مجتمعهن، محاصرات في أفكارٍ مسمومة لداعش وعندما يرون الحقيقة أفن متأخرات للغاية ويرون أنفسهن في حجاب أولئك الذين لايشتمون رائحة الإنسانية وسيكون لكل واحدة مصير قابل للقراءة ومعرفة. تروي هذه الرواية جرائم داعش في ظل قصة رومانسية، وتتحدى بعض قضايا الجتمع من وجهةالنظر لامرأة طليقة. تحاول هذه المقالة دراسة عناصر الرواية متمسكا بالمنهج الوصفي التحليلي. تظهر النتائج أن عنصر الحبكة وعناصرها المكونة هي العناصر الأكثر استخدامًا لقصة حبيب داعشي. رؤية القصة من النوع الثالث للراوي الذي رواه الراوي المخفي وغير المرّّز في السرد. في هذه الرواية، يتم نقل فضاء القصة إلى القارئ من خلال مشهد دراماتيكي، لأن عنصر الحوار واضحا طوال القصة والكاتبة لا تصف ما يمكن استخدامه لفهم الفضاء والبيئة. أيضا مونولوج في هذه الرواية هو صغير جدا.

أكثر من أنواع الأدبية المكتوبة الأخرى تعمل كأمثلة يســتطيع المتمع أن

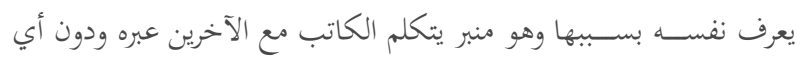
شك هذا السبب الرئيسي لإلتنفات الأسلوبيين مها.

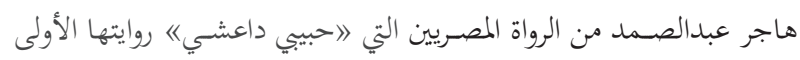

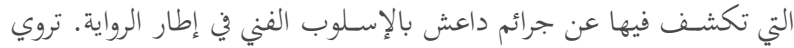

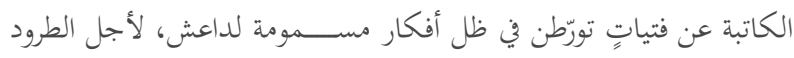

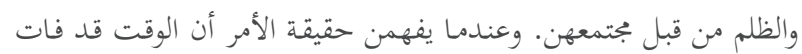
ويرون أنفسهن في حضن الذين لايجدون في ضمايرهم روح الإنسانية بحيث مصير كلهن يستحق للقراءة ويكون اعتباراً للآخرين.

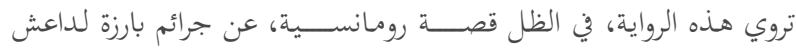

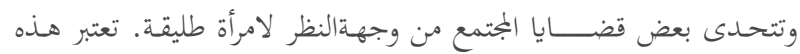
الدراسـة مهمة لأغها بالإضـافة إلى فتح آفاق جديدة في نظرة إلى الروايات، فهي تدرس تماسك موضوعي وشكلي ومضموني للرواية. يكون هذا التحليل

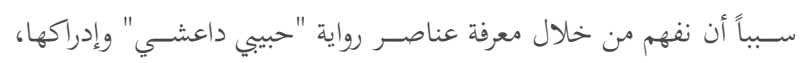

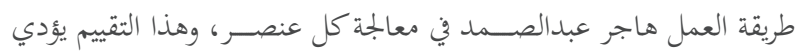
إلى أن نعرف قيمة روايتها من حيث المتوى.
الكلمات المفتاحية: الرواية، عناصر القصة، الصراع، هاجر عبدالصمد، حبيبي داعشي

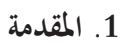

القصـة هي مصــطلح عام لوصــف الأحداث، من الممكن أن تكون هذه الأحداث حقيقية وها زمن ومكان محدد أو هي إبداع لقوة الخيال البشري.

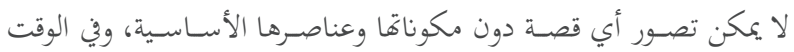
نفسه لانستطيع أن نتصور إعتباراً وقيمة لعناصر القصة وأجزائها خارجاً من وند السياق. إن وجود عناصر القصة تؤدي إلى تكوين القصة وتشكيل بنيتها، ويجب أن تشمل كل قصة على هذه العناصر لكيتتكون القصة، متماسكة ومقبولة. الرواية كلام الكاتب المنقول الذي يلبس ثوبا لغويا ويتغير البناءات والأصـول

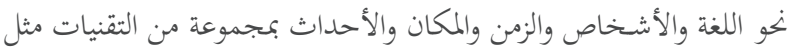
الرواية والوصـف والصـراع وهو أسـلوب كالمتزايد في الأفلام السـينمائية التي يتصــارع فيها الأشـخاص حينا ويفصـلون حينا آخر حتى ينتهى النص إلى آخره العادي بالأناقة التامة.

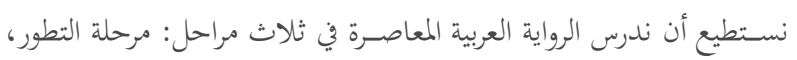

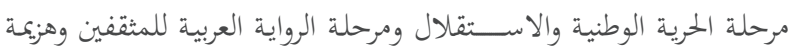
الوطنية بعد يونيو وحرب اللبنان، لكن يبدو بالنظر، يجب أن تضـاف إليها

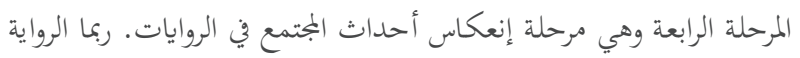


أن تنقذ نفسها. تخاف ليلي من القضية، فتذهب إلى عمر في منتصف الليل

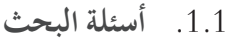
وتطلب المساعدة منه.

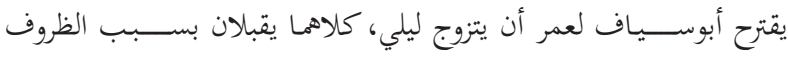

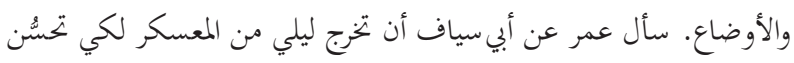

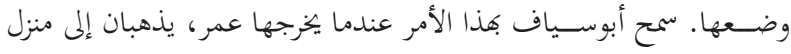

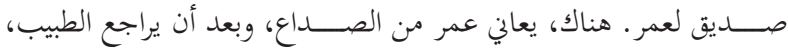

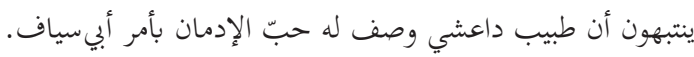

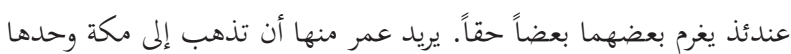

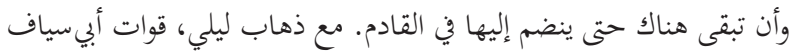

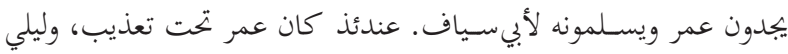
تتنظره في مكة. بعد حوالي عامين قد جاء عمر إلى مكة ووجد ليلي وذهبا

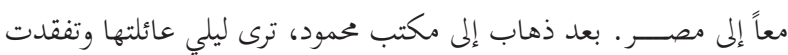

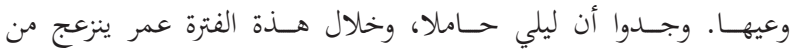
الكوابيس. لأنه قد قتل والدةً أمام عيون طفلها مكرهاً في الفترة التي كان النان

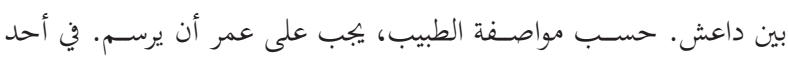

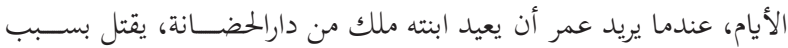

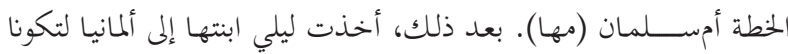

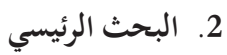

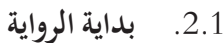

واحدة من القضـايا في دراســة الرواية هي طريقة كيفية بدايتها التي تصـبح واضحة مع الدقة والنظرة العميقة فيها ومقارنتها مع القصص الأخرى. يمكن أن نفهمَ الاختلافَ وتنوع القصة مع الاهتمام بكيفية بدايتها ثم نستطيع أن ننقســم القصـص على أسـاسـها (فِّالعراقي، 1378: 149). إن بداية الرواية الحالية هي مزيج من تقديم ملخصٍ من القصـة وخلق أسئلة غامضـة فئس

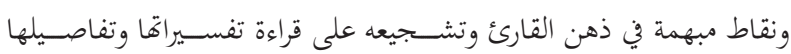

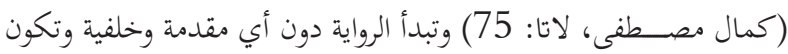

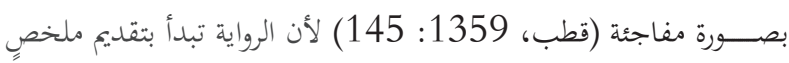

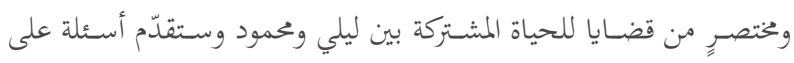
القارئ مثل: لماذا طلق محمود ليلي؟ بحيث تزداد رغبة القارئ إلى القراءة مواصـلة القصـة ومن جانب الآخر تبدأ القصـة دون أي مقدمة لإن ماهية الموضوع تعبر عن الحب والغرام، فيميل القارئ إلى قرائتها مستمرا.

2.2. الشخصية

كلمة الشخصية مترجمة عن اللغة الفرنسية في الأصل التي استخدمت فيها كلمة شخص (personne) في القرن الثانيعشر الميلادي (أنظر الجيلان، 2009: 3). حقيقةالأمر أن 》الثـــصـية عنصــر مهم في عملية البناء الفني، وترجمة الباطن غيرالمرئي للفنان، عن تشكيل درامي للحدث، والفكرة، والهيكل الفني العام، وللأثر الفني برمته/ (ابراهيم، 1983: 71) 
حاضــرة في فاية القصــة وبدايتها مما يعني أن عملية الأحداث لاتؤثر فيها

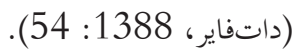

2.3 - 2. - n الوؤية

تقدم الرؤية أو زاوية السـرد طريقة يقدم بها مؤلف مواد قصـته الى المتلقي، وتمثل في الواقع ءإلى علاقة الكاتب بالقصـة (ميرصـادقي، 1380: 385).

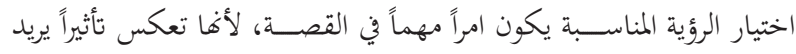

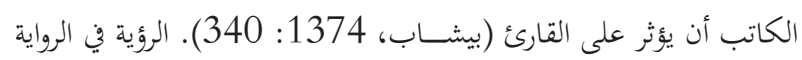

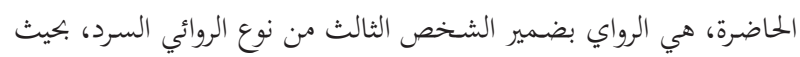

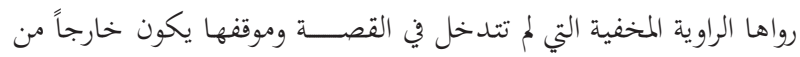
الســـد. اللهجة الوحيدة المســتخدمة في هذا النوع من النظرة هي اللهجة

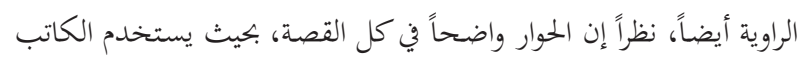

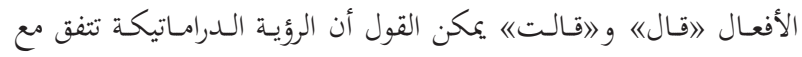

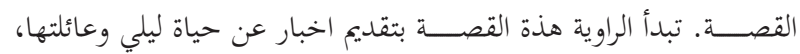
ويصور حياهما مع زوجها محمود ويجذب القارئ إلى فضاء القصة.

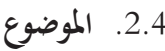

يشـمل الموضسوع على ظواهرٍ وأحداثٍ تخلق القصسة وترسم الفكرة (عبدربه، 1979: 96). هذه القصــة حقيقية 》القصـص عص الحقيقية تنبع عن الحياة

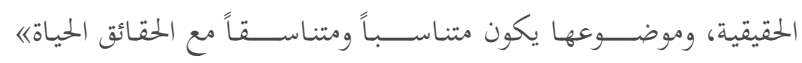
(ميرصادقي، 1386: 85). تدور هذة القصة حول حياة امرأة طليقة، التي

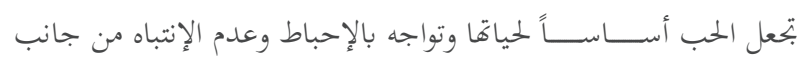

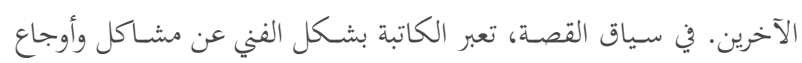
وأحزان الناس وترتبط القصة إلى داعش. يتناول قسم أكبر من الرواية بالتعبير

$$
\text { عن جرائم داعشيين وسلوكهم القبيحة. }
$$

2.5. الفكرة (المفزي)

الفكرة عنصر أساسي في كل القصة وهي: 》الهدف الذي الكاتب عرضه في

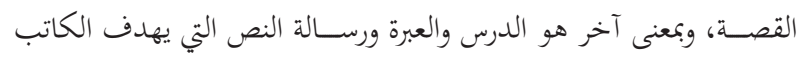

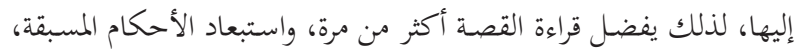

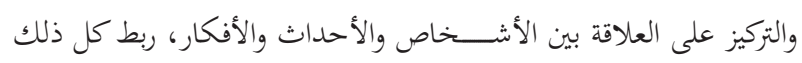

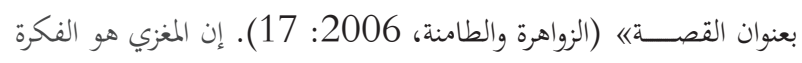
الرئيسية والمسيطرة، الذى أداه الكاتب في القصة. يمثل تم كل العمل الاتحاه

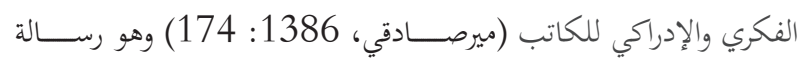

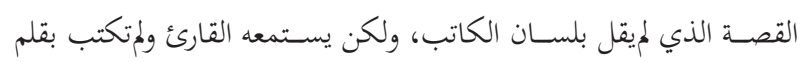

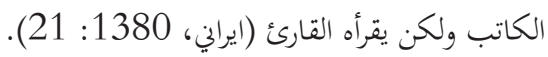
تتكون هذه القصة من ثلاثة أقسام: تبدأ بتعبير عن الحياة لأسرة ليلي، تعتبر

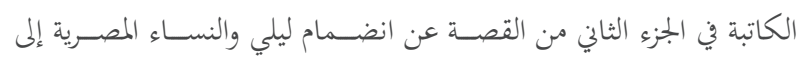
داعش وفي القسم الثالث تتكلم الكاتبة عن عودة ليلي وعمر إلى مصر، تبرز الفكرة الكاتبة اكثراً في قســمي الأولى والثانية. في الجزء الأول، تعبر الكاتبة
لها العديد من العناصر، وأهمها هو عنصر الشخصية 》الشخصية هي من

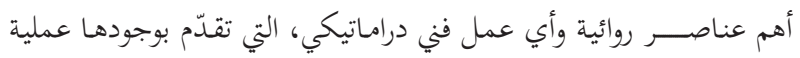

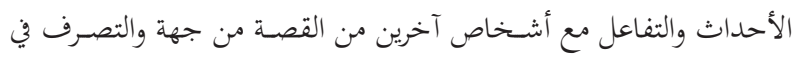
أماكن وجغرافيات مختلفة من جهة أخرى《 (بوررضائيان وآخرون، 1390:

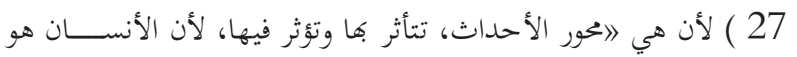
مناط الكليف ومعتمد التغيير وأساس التوجية《) (عليان، 1413: الشخصية الرئيسية أو الجوهرية: هي الشخصية التي يتمحور حولها الأحداث

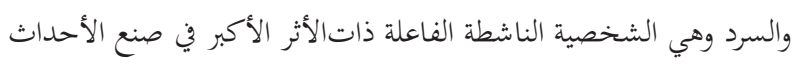

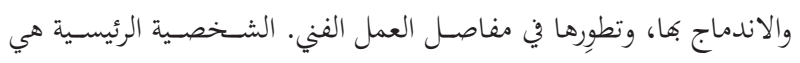

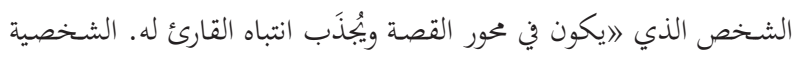

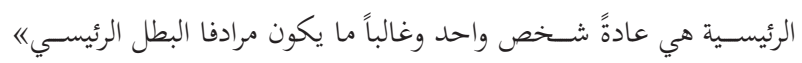

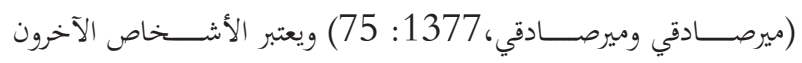
شخصيات ثانوية. اأن الشخصية الثانوية لاتظهر في أي قصة إلا اذاكانت

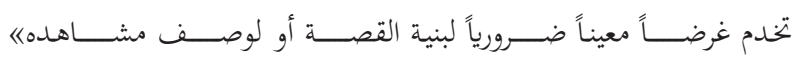
(تورنلي، 1992: 95). أما الشـخصـية الثانوية فهي تحمل أدواراً قليلة في الرواية وأقل فاعلية، افهي التي تضـيء الجوانب الفنية للشـخصسية الرئيسية

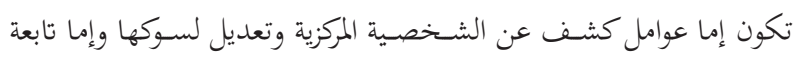

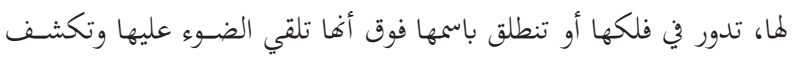

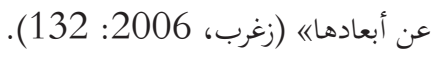

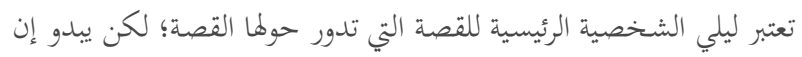

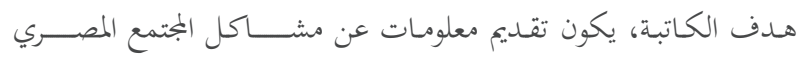
والاســتخبارات حول داعش إلى القارئ في ثنايا الرواية. ليلي تكون رمزاً

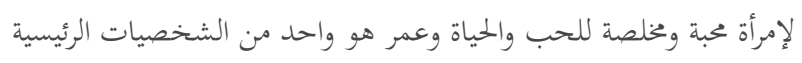
الأخرى في الرواية الذي ظهر في الجزء الثاني منها، يعني عندما تلحق ليلي

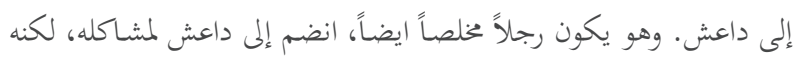
ساخطاً عن الأوضاع هنا. محمود، زوج الأول لليلي، هو يكون شـحصـية ثانوية؛ إنه شـحصـية أنانية تقريبا لأنه تزوج سراً رغم زواجها، دون أن تعلم ليلي سبباً لطلاقها.

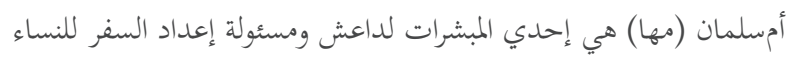

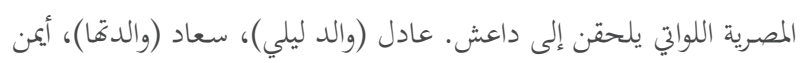

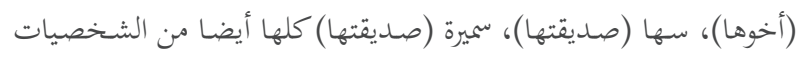

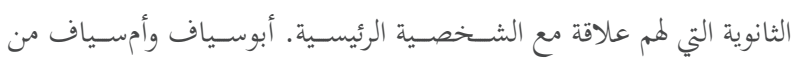

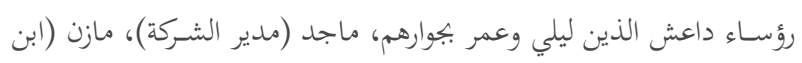

سها)، الحراس و ... كلهم من الشخصيات الثانوية أخرى في القصة. من وجهة أخرى، يعتبر عمر وليلي من الشخصصيات الديناميكية في الرواية؛ 》اتطلق الشخصية الديناميكية على شخصية تتغيّر من خلال القصة تدريجيًا، ويؤثر مسار الأحداث عليه《 (نجم، 1963: 104 104).

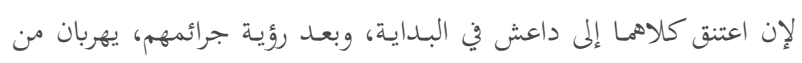

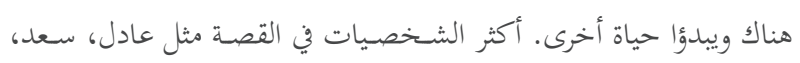

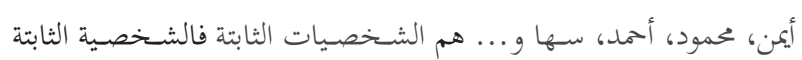


النموذج الآخر للوار يكون حينما تسأل أمسياف عن ليلي، هل تقصدي

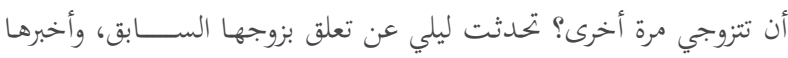

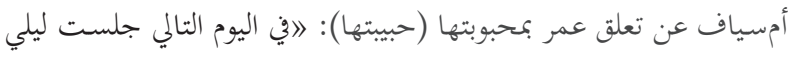

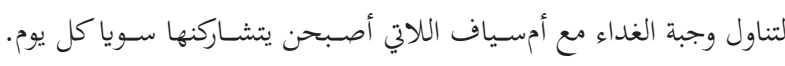

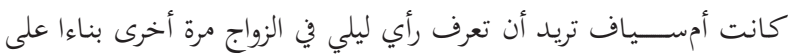

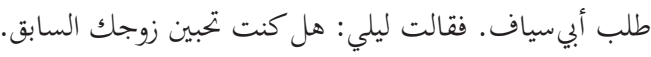

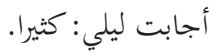
قالت أمسياف: ألم تفكري أن تتزوجي مرة أخرى؟ أجابت ليلي: لقد هربت من مصر كي لا أتزوج مرة أخرى؟

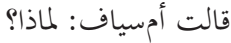
أجابت ليلي: إن كان قلبي معلقا برجل فكيف أتزوج رجلا آخر. ابتسمت أمسياف وهي تقول هل هي لعنة الفراعنة أم ماذا؟.

$$
\text { استفهمت ليلي وقالت: ما الذي تقصدينه؟. }
$$

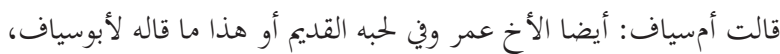

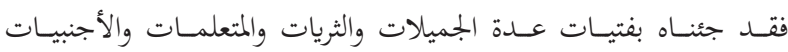
والعربيات، ولكن كان جوابه الرفض الدائم وكان يقول أن قلبه تملأه أمرأة ولا

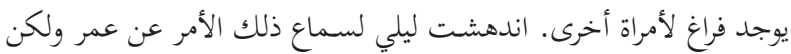

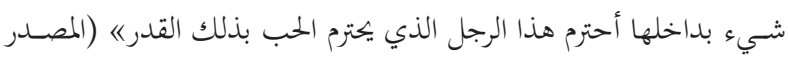

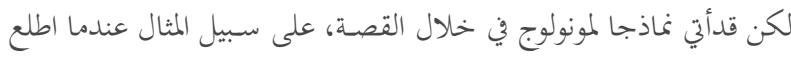
عمر عن خطةٍ رسمها أبوســياف لليلي، يبحث عن الطريق لجذب ثقة ليلي لئي

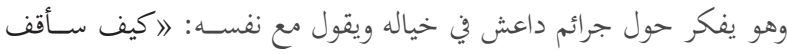
أمامها وأقول: أنا الداعشــــي الذي تلوثت يدي بد بدم الأبرياء .. أنا القاتل

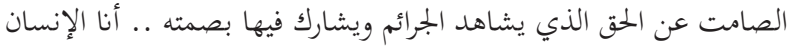

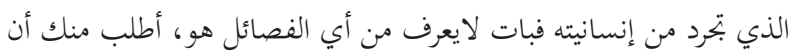

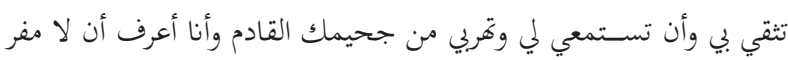

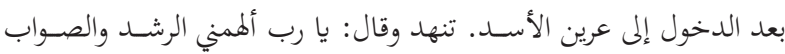

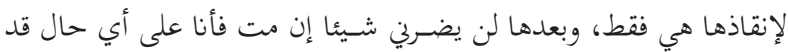
تعبت من تلك الحياةه (عبدالصمد، 2015: 2015: 53 ).

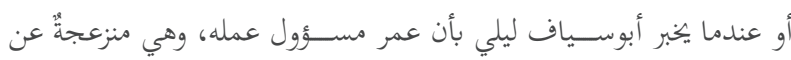

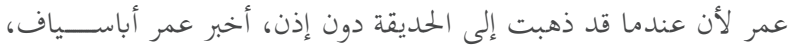
وتقول ليلي في نفسها، إن عمر جاسوسا: اقالت ليلي في نفسها: بالطبع

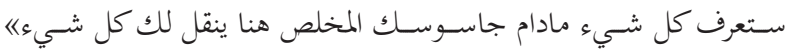

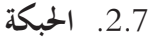

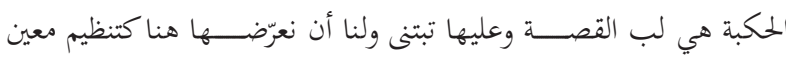

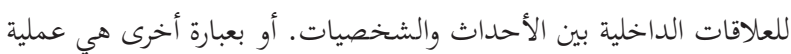

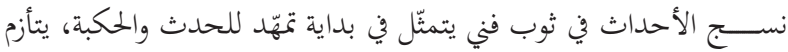
فيها الحدث وفي غاية يكون فيها حلّ الأزمة. الالحكبة هي سلسلة الحوادث

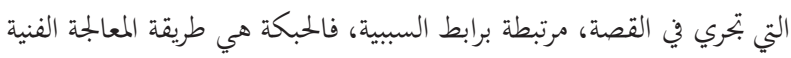

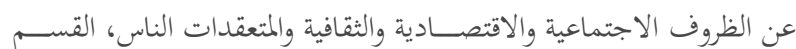

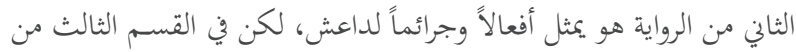

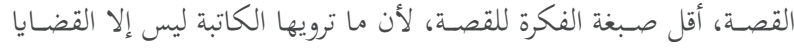

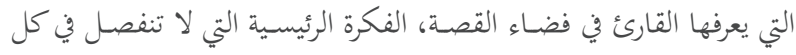

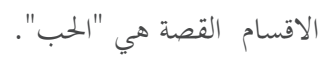

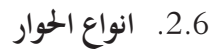

الحوار هو ما يدور من حديث بين الشـصصيات في القصـة، أو مسـرحية،

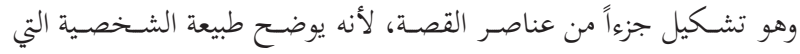

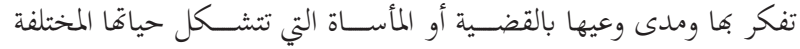

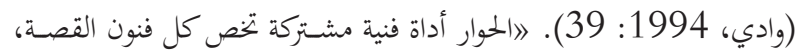

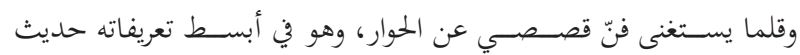

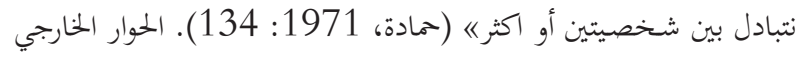

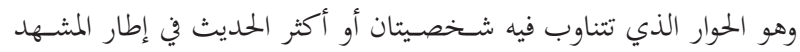

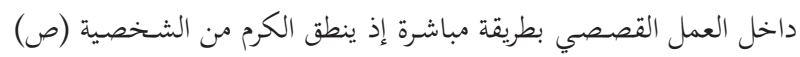

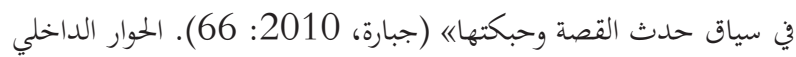

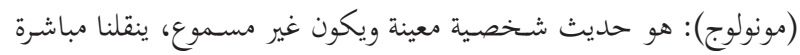

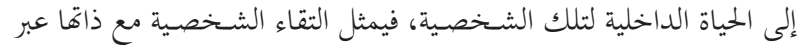

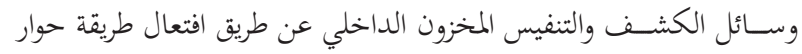

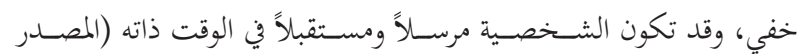

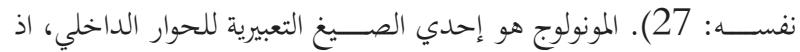
يهـدف إلى كشـــ لواعج الذات، ودواخلها، وماتســتنبطه بداخلها

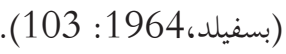
قد يسـيطر الحوار الخارجي على كل القصــة الحاضــرة، كأن تروي الراوية

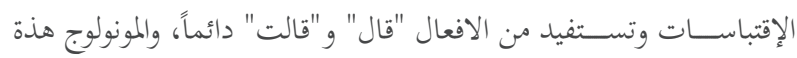

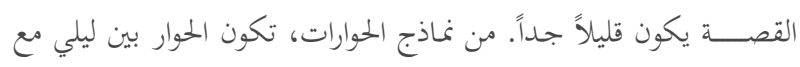

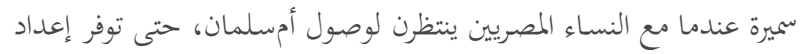

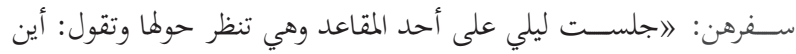

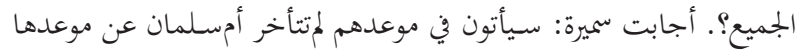

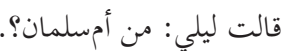
أجابت سميرة: هي المسئولة عنا وعن إنهاء ترتيبات السفر.

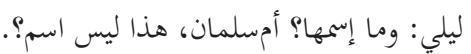
سميرة: هي لمتخبرنا سوى بهذا الاسم وأيضا ترتدي النقاب ولا تخلعه أبدا. تعجبت ليلي وقالت: لماذا؟. سميرة: تقول أن تلك إجراءات أمنية. أومأت ليلي برأسها متفهمة ثم قالت:لم أكن أتصـور أننا سـتنقابل في مكان أنقان

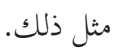
ضـحكت سميرة وقالت: كنت تعتقدين أننا سـنقابلهم في خيمة أو شيء شبيه بذلك؟ ابتسمت ليلي وأجابت: لن أكذب، فأنا بالفعل تصورتُ شيئا كهذا《 (عبدالصمد، 2015: 28). 


\subsection{2. الصراع}

الصراع جوهر لكل قصة ولكل العمل السردي الآخر. والصراع يكون بمعنى

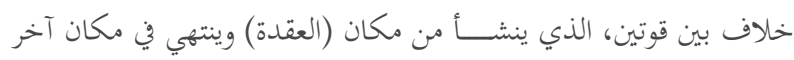

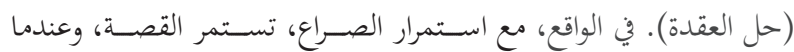
ينتهي، تنتهي القصـة (سـنابور، 1383: 27- 20-30). عندما يمسـك مدير

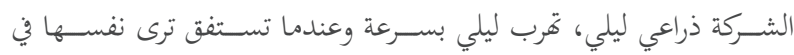

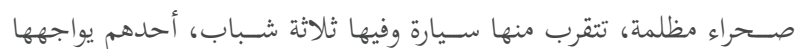
بصــراع الفيزيايي: ا(فجاة اقتربت ســيارة وابطأت وحين اتضــحت الرؤية وجدقمم ثلاثة شـباب اوقفوا ونزل أحدهم، وفي تلك اللحظة احكمت ليلي

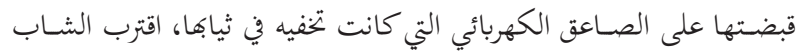

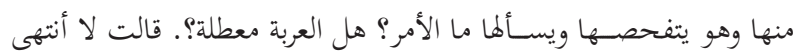
الوقود، هل يمكنك أن تاتي بوقود لي وتسـاعدني؟. ضـحك ولك الشـاب وقال: بالطبع يمكني مسـاعدتك مادمتي ستسـاعديني وثم نظر إلى أصدقائه وغمز

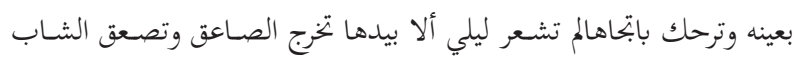

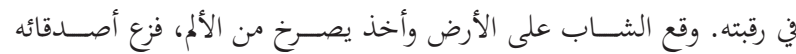

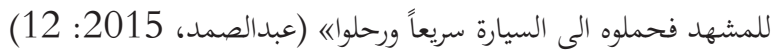

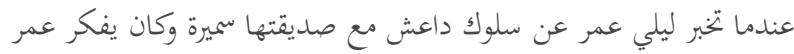

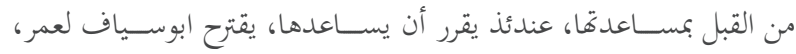
لأجل الحالة النفســية لليلي، أن يتزوج بليلي، بعد زواجهما، يقرران لفرار

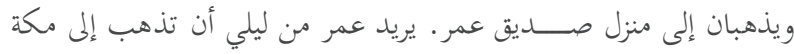

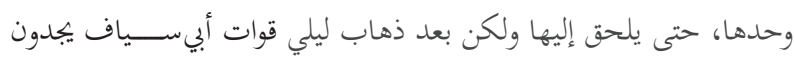
عمر ويسلمونه به، ويبدأ صراعه مع أبيسياف: اقال عمر: إن كنت تقصــــد بالمعاملة الحســــنة هو إقتيادي إلى هنا دون

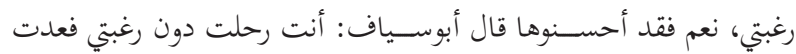

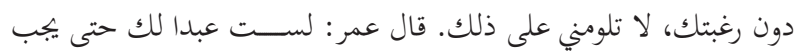

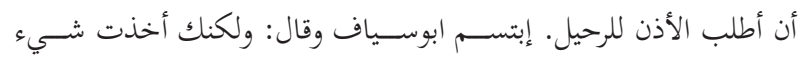
يخصني مع رحيلك، أخذت ليلي. ضحك عمر وقال: ألا تتذكر لقد زوجتها

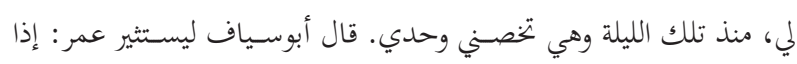

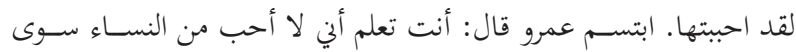
واحدة وقد ضـــاعت مني منذ ســـنوات، فلا تقلق لقد طلقت ليلي قبل

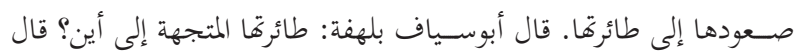

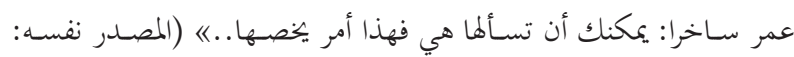

.$(88,87$

وبعد قتل عمر ســيئت حال ليلي وعندما تكون في المســشــفى، تذهب أمســلمان، التي خططت قتل عمر وتنوي اختطاف ملك، لزيارتا. في هذه

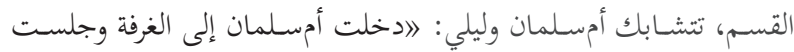
على الكرسـى بجوار فراش ليلي وســـ ذهول الأخيرة. إبتلعت ليلي ريقها وصرخت بها: ما الذي تفعلينه هنا؟ قالت أمسلمان: أهدتي قليلا وإن كنت

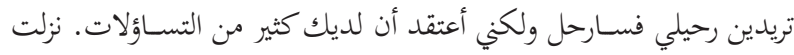

التي يجريها الكاتب على المادة الأولية للقصـــة) (نجم، 1963: 63) أو بعبارة أخرى لاهي ذلك العنصر الذي يضفي شكلاً على الفعل الذي يمثّل،

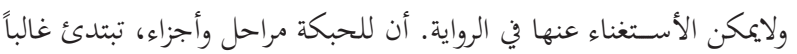
بمقدمة تنتقل منها إلى الحادثة حيث تبلغ ذروتا ثم تصــلـل إلى الحلّ وهو

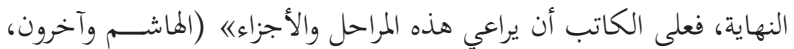
(106:1966 تتكون حبكة كل قصـــة من عناصـــر متعلدة، وقد يبين بالتالي بصــورة المنفصل:

2.7.1. العقدة

العقدة هي تشكيل واشتباك القوات المتعارضة في القصة، حيث يواجه بطل القصة بالمشاكل (سبزيان وكزازي، 1388: 109). تأتي العقدة في الرواية

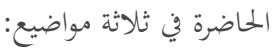
ليلي هي امرأة طليقة في المجتمع المصــري ينظرون إليها نظرة سـلبية ويرقبون

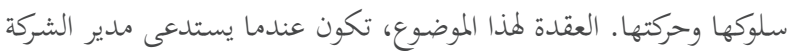

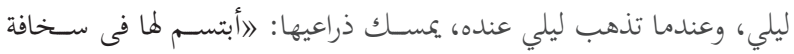
وهو يقترب منها أكثر ويمسـك ذراعيها ويقول: أواسـيك. صـرخت به: ما بالك ما بال الجميع؟ ثم خرجت مســـرعة من مكتبه وأخذت حقيبة يدها

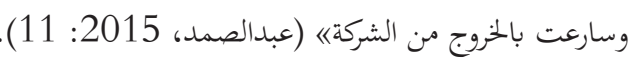

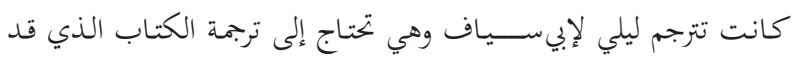

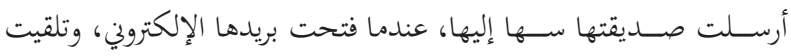
رسالة من سميرة التي انضمت إلى داعش معها، وهي قد أرسلت إليها شهرًا

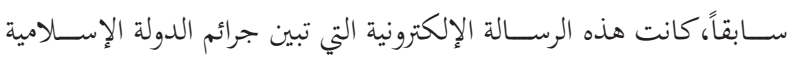

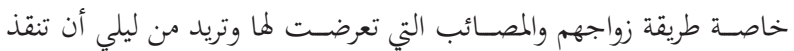
نفســها. تخاف ليلي من القضــية، فتذهب عند عمر في منتصــف الليل

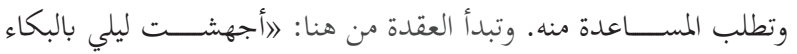
وارتمت على الأرض وأمســــت بقدمه وهي تقول أرجوك أتقذني، أرتبك

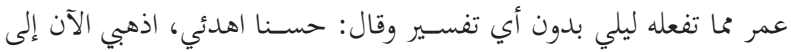

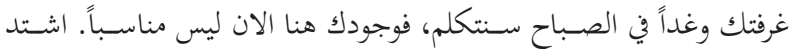

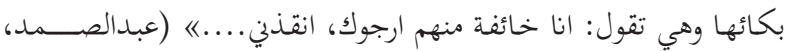

(63: 2015

بعد أن تبدأ حياة المشـتركة ليلي وعمر، في مصــر، حينما تذهب إبنتهما

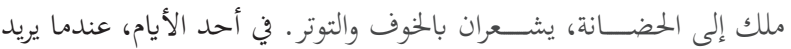

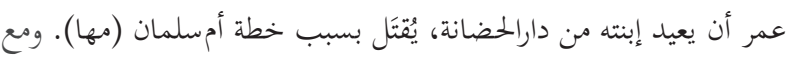
قتل عمر، تبدأ العقدة في موضوع أخرى: اأوقف عمر السيارة أمام الحضانة وجلس ينتظر مع ليلي خروج ملك، بعد قليل فتح البوابة وبدأ الأطفال في

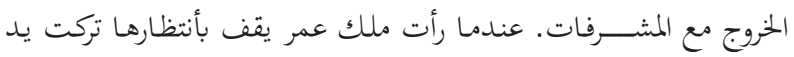

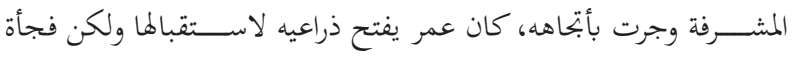
انطلقت رصاصة خائنة إلى صدر عمر المفتوح لابنته فخرّ سريعاً تحت أقدام ملك《) (المصدر نفسه: 114). 
القارئ ولكنه ما إن وصل إلى نتيجتها في النهاية، يتقبّلهاه (سليم الحظطيب،

2009: (100) (200)

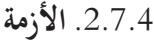

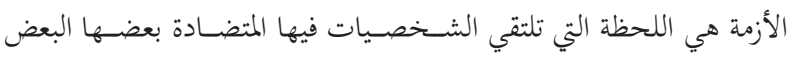

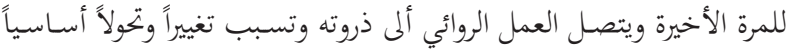
في حياة الشخصية الحورية أو أشخاص آخرين، حيث ينتهي هذا التغيير إلى الى

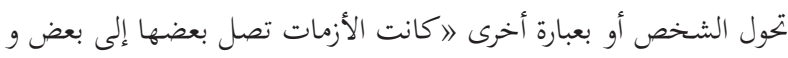

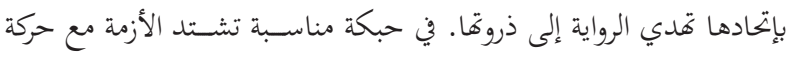

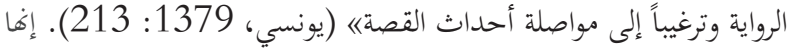

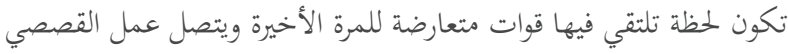

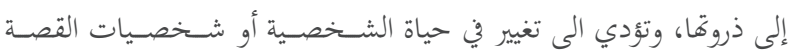
ويقومون بإجراء تغيير غائي في المســار الرئيسي من القصــا (ميرصـادقي، 1380: 76) بعبارة أخرى، أزمة القصــة هي لحظة أو فترة زمنية خلالاما يتحدث تغيير غائي للقصة (يونسي، 1379: 1370: 348).

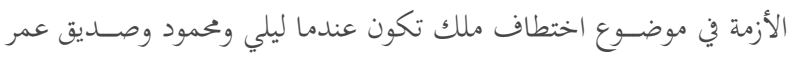
(محمد ســوري) يجدون ملك وهي بجوار أمســلمان، وأمســلمان بمجرد إن ان تراهم، تجعل سكينة على عنق ملك:

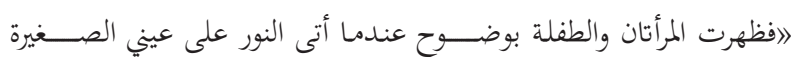

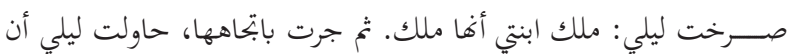
تجنب الفتاة لكنها كانت تتشسبث بالمرأة وكانت المراة تصـرخ: إنها ابنتي أنا. صـسـد محمود إلى الطابق الأول ومعه ليلي التي كانت تربتف وقام رجال

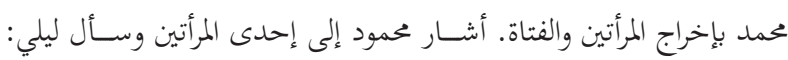

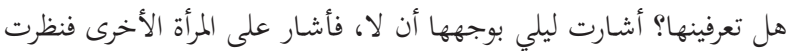

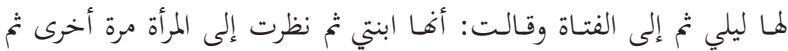

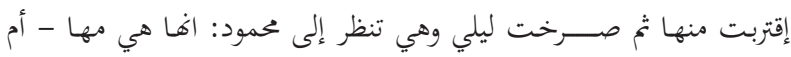

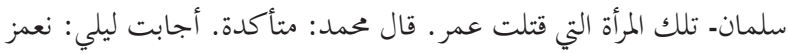

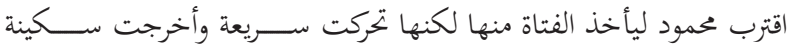

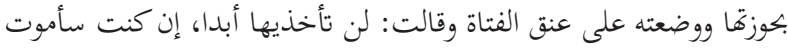

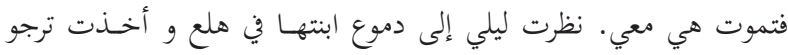
أمسلمان ألا تفعله (عبدالصمد، 2015: 128)

\subsection{5 - - 2.5 - حل العقدة}

حل العقدة يعني أن الراوي ايظهر حل القصةه (قطب، 1359: 159).

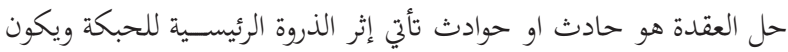
بكعنى حل عُقد الحبكة في فاية القصة والمسرحية (ميرصادقي وميرصادقي،

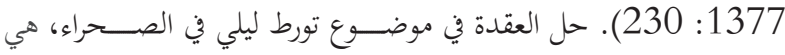
عندما يأتي محمود ويأخذها: الامرت نصف ساعة حتى قطعها محمود وقال: ليلي أشعلى أضواء السيارة. بعد دقائق وصل إليها محمود ونقر على النافذة

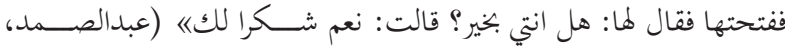

دموع ليلي: هل أنت من قتل عمر؟ إبتسمت أمسلمان وقالت: أنا لا ألوث

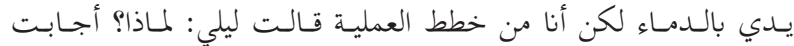
أمسـلمان: هذا حسـاب قديم كان يجب على عمر تســيده. صـرخت بها

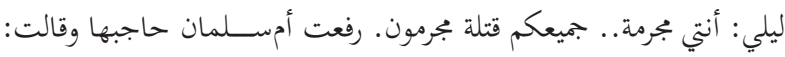

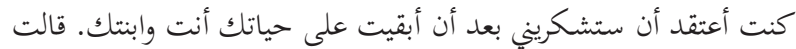

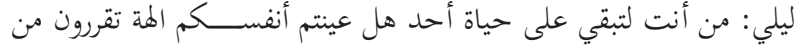

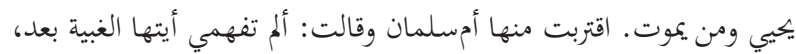
نحن جنود الله في أرضسه. قالت ليلي: وكيف يكون جنود الله بهذه القسـوة.

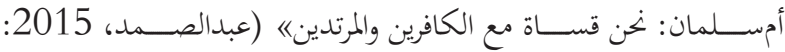
$(116,115$

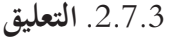

إن الشك والتوقع فيخطة القصـة بجبر القارئ بهذا السؤال عن نفسهـ "ماذا سيحدث بعد ذلك؟" أو "ماذا سيحدث في النهاية؟" حتى يستمر القصة، هناك طريقتان لخلق الشك والتوقع:1 - طرح اللغز 2- وضع البطل في شك ادك.

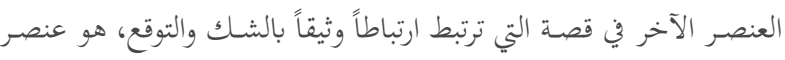
"المفاجأة". تقاس مفاجأة القصـة بالأحداث غير المتوقعة في القصــة (أنظر: برين، 1378: 29-36) ونظرة لتحدث أحداث عديدة في الرواية، فإننا

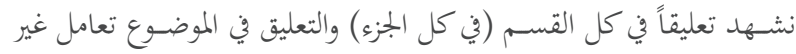

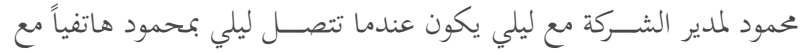
هاتف الرجل العجوز الذي يراها وينوي مساعدةها. بعد ذهاب الرجل، ليلي وحدها تكون في انتظار محمود: اردت ليلي: أرجوك أنا خائفة جدا الظلام هنا دامس قال محمود: حســنا أغلقي عينيك، هلا فعلتي؟ ردت عليه: نعم قال: اغلقي الآن الأنوار دون

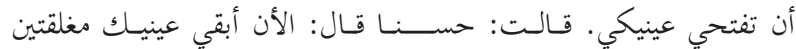

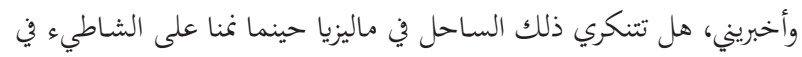

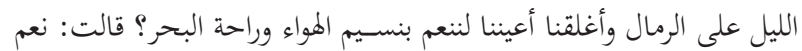
أتذكر قال: تخيلي نفسك هناك. بدأ يتسرب الأطمئنان إلى صومةا وهي تقول: حسنا قال: جيد، الآن هل

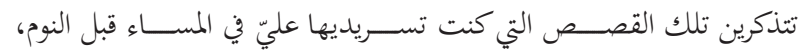

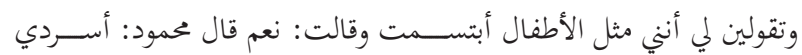

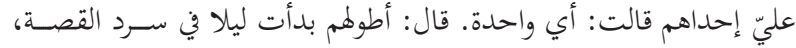

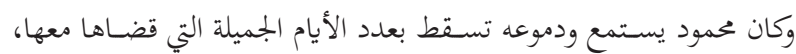

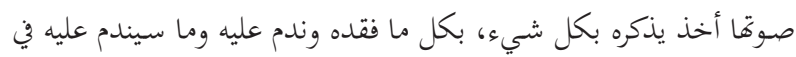
المستقبله (عبدالصمد، 2015 :14 و 15). التعليق في موضــوع هروب ليلي وعمر عن داعش (أنظر المصــــر نفســه:

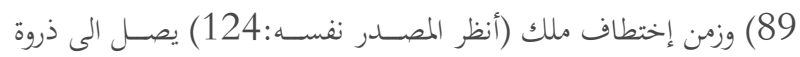

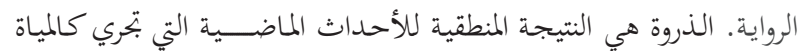

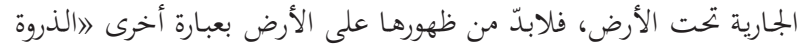

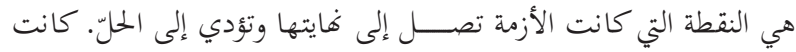

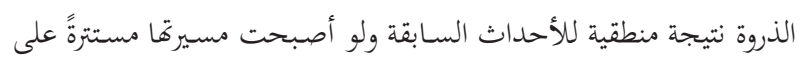




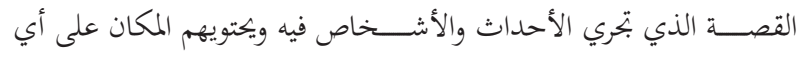

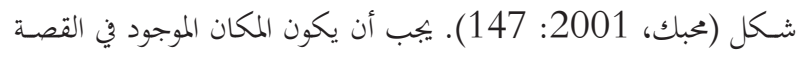

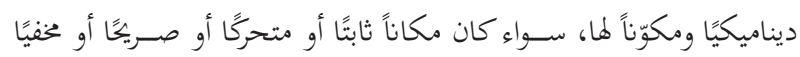
في الرواية الحاضرة، قداستخدمت الكاتبة كلمة "المشفي"، على سبيل المثال، عندما فقدت ليلي عمر، تنتقل إلى المســتشــفى للعلاج: الققد حذرها

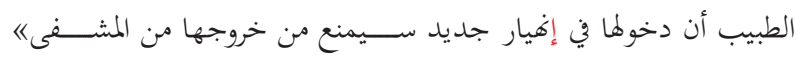
(عبدالصمد، 2015: 115)

عندما صديق عمر، محمود و ليلي يجدون ملك في جوار أمسلمان، وضعت

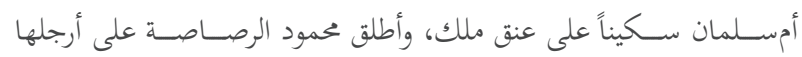

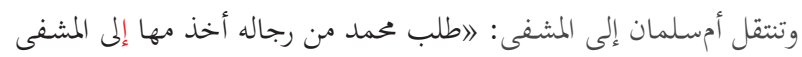

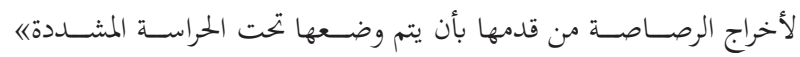

$$
\text { (المصدر نفسه: 128) }
$$

عندما تكون ليلي بإنتظار عمر في مكة، بعد أن نفدت أموالها، وتتزامن مع

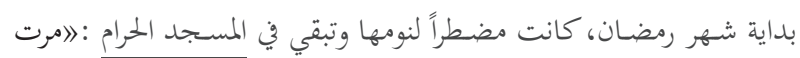
الأيام وبدأت نقودها تنفذ ولم يعد يبقي معها إلا القليل فتركت التي كانت

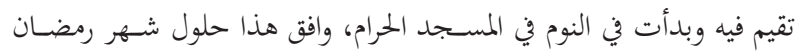

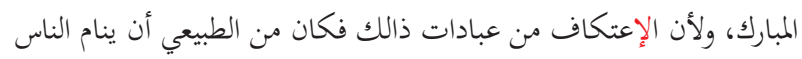

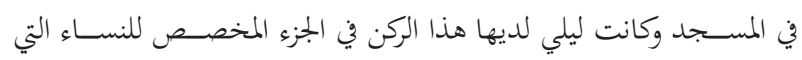

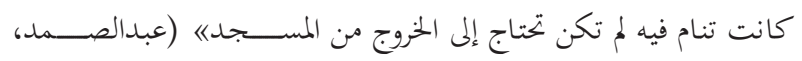

(89:2015

روضةالأطفال هي واحدة من الأماكن الإختيارية التي ترسل ليلي ملك اليها

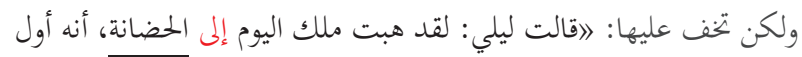

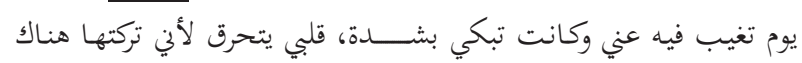

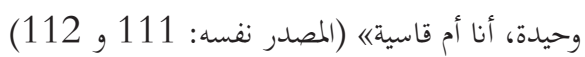
عندما تذهب ليلي إلى منزل أبيسـياف، في اليوم الأول تذهب إلى الحديقة

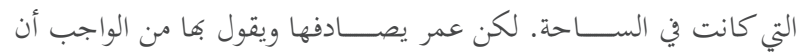
تذهب إلى الداخل: إكانت تتمشي في الحديقة المضيئة بالأنوار الهادئة وهي

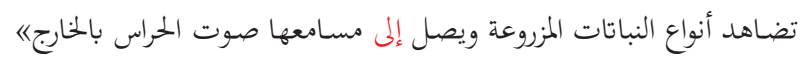

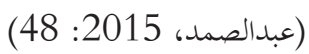
عندما تنتقل ليلي الى عاصــمة الخلافة لداعش تذهب عند أبيســياف، تصف الكاتبة، مدينة الرقة وشوارعها، التي تقع على الضفة من فر الفرات:

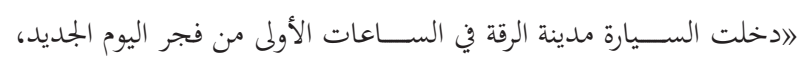

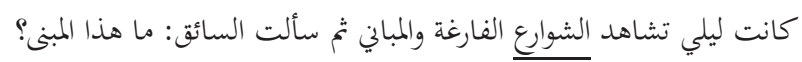
أجابها: هذه المحكمة وإخذ يعرفها على المدينه ويقول هذا بت الزكاة وهذا

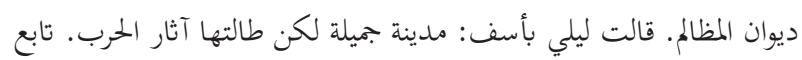

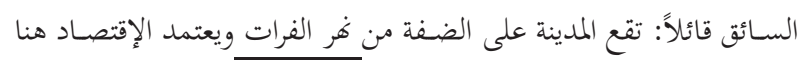

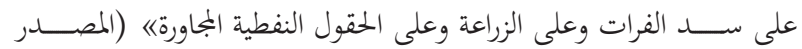
نفسه: 46 و 47)
إن حل العقدة في الموضوع هروب ليلي وعمر، يكون عندما ليلي في أصعب اللحظات في انتظار عمر،حتى يصل عمر : إفي ليلة الخامس والعشرون بعد صــلاة المغرب كانت ليلي تقف عند بوابة الملك فهد تراقب الحمام وهو

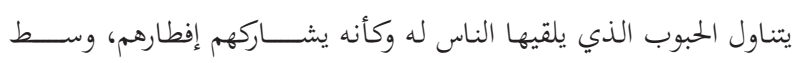

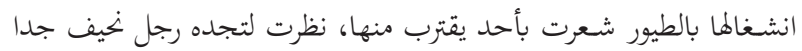
غائر العينين يجيطهما السواد وشفتين متقشفتين ذو بشرة باهنة يرتدى الزي برتي السـعودي، تلاقت عيناهما فإذا بالرجل دموعه تسـقطة، وقف أمامها وقال:

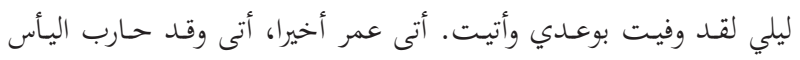
والســن والظلم والتعذيب والقهر بحبه، أتى ليثبت أكثر النظريات إثباتا أن ولن

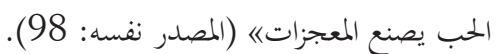

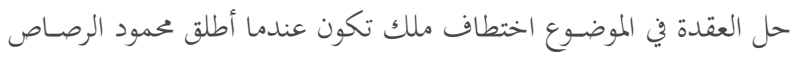

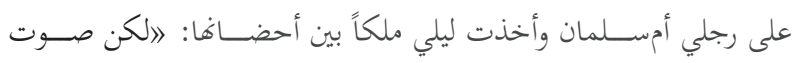
رصاصه اهى كل شيء. خرّت أمسلمان على الأرض بعد أن أطلق محمود

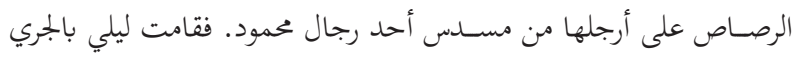

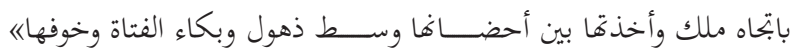

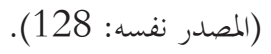

\section{8. المشهد ورسم المثهد}

مشهـد القصة يكون زمناً ومكاناً لوقوع عمل القصة، بمعنى أخرى، المشهـد

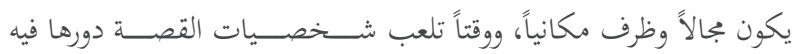
(مستور، 1386: 46-47) وهو يكون مطاراً لمشاجرات وبجالاً لأعمال

الشخصيات وخطة لمؤامرات (براهني، 1384: هناك طريقتان لنقل المشهد وفضاء القصة للقارئ: الف) التلخيص او الإقتصار (الإختصار) ب) المشهد الدراماتيكي

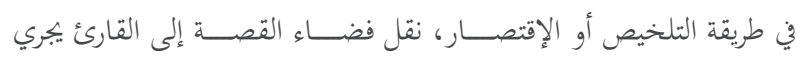

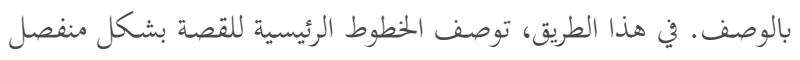

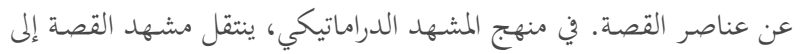
القارئ بإسـتخدام الحوار بين الشــخصـيات. إن إثارة التهييج والفرح عند لئد

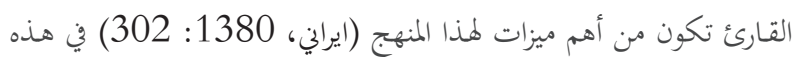

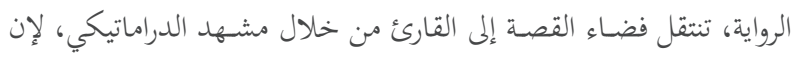
يشاهد في القصة برمتها عنصر الحوار وفي خلال القصة لا تصف الكاتبة أي شيء، يدل على الفضاء.

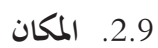

إن المكان باعتباره أسـاسـي من العناصـر المكونة للعمل السـردي، هو في عمقه مجموعة من العلاقات والشـخصيات التي يستلزمها الحدث والديكور الذي بتري فيه الأحداث (بحراوي، 2009: 31). الايشكل عنصر المكان

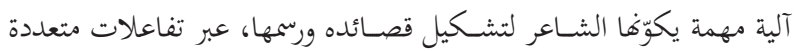
وتحولات أسـاسية) (النابلسي،1994: 92). إن المكان من أهم عناصر 
الدراماتيكي؛ لأن يشاهد عنصر الحوار في كل القصة. الزمن في هذه القصة هو موضوع تدركه الكاتبة تمامًا ولم تذهل منه.

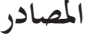

[1] ] ابر اهيم، نصرمحمد (1983)، البناء الفني في القصة السعودية المعاصرة، الرياض:

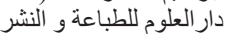

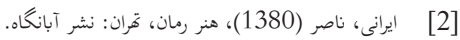

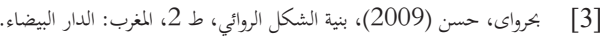

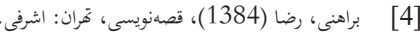
[5] ] بسفيلد، روجرم (1964)، الحوار في القصة والمسرحية (للمسرح والإذاعة والتلفزيون والسينما)، ترجمة دريني

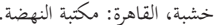

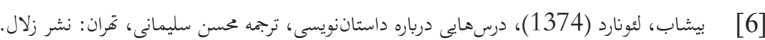

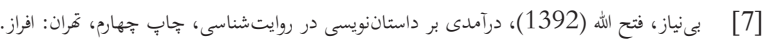

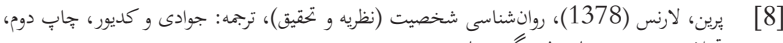

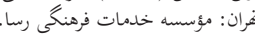

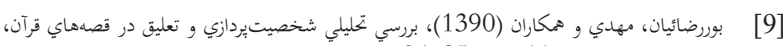

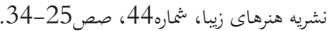

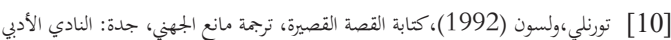

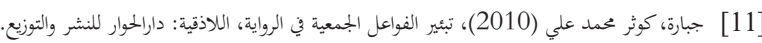

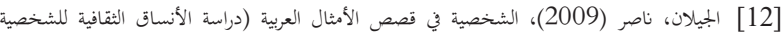
العربية)، جدة: الناديب الأدبي.

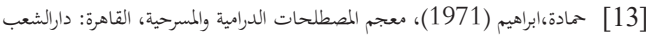

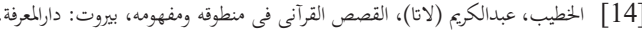

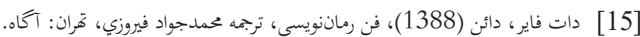

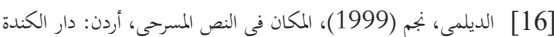

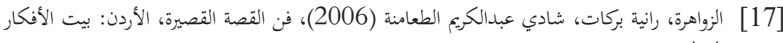
الدولية.

[18] [ زغرب، صبيحة عودة، (2006)، جماليات السردي في الخطاب الروائي، عمان: داربحدلاوي.

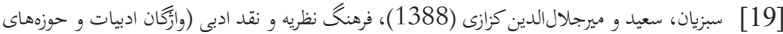
وابسته)، خران: مرواريد.

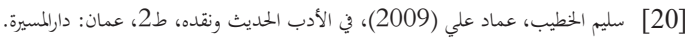

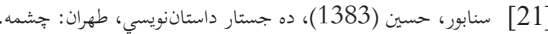

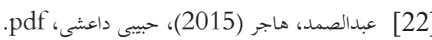

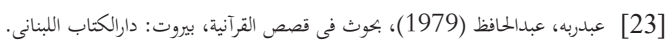

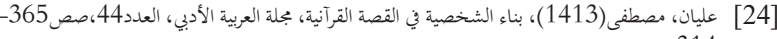
.314

[25] فعالعراقى، حسن (1378)، داستانهاى قرآن در الميزان، ثران: نشر سبحان.

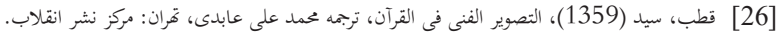

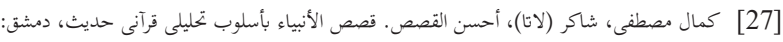
دار المعرفة.

[28] عبك، الممد زياد (2001)، دراسات نقدية من الأسطورة إلى القصة القصيرة، الطبعة الأولى، دمشق: دار علاء الدين.

[29] مرتاض، عبدالملك (1988)، في نظرية الرواية، بحث في تقنيات السرد، الكويت: الجلس الوطني للثقافة والفنون والآداب.

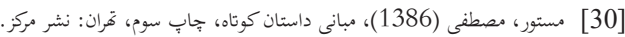

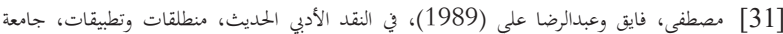

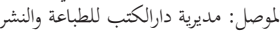

[32] [ ميرصادقى، جمال (1386)، ادبيات داستانى قصه، رمانس، داستان كوتاه. تُران: انتشارات سخن.

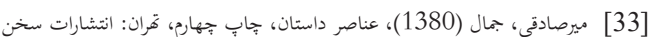

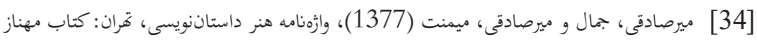

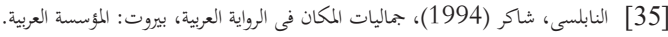

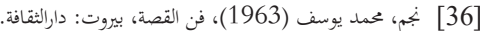

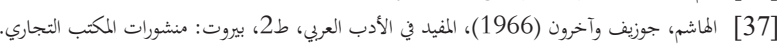

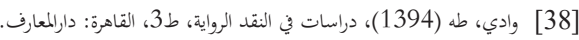

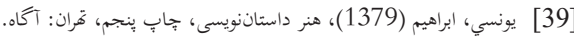

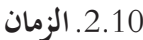

الزمن هو تحديدكل مرحلة تمضي لحدث سـابق إلى حدث لاحق (مرتاض،

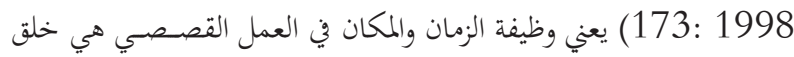

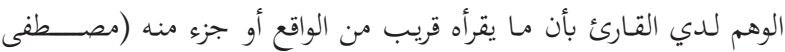

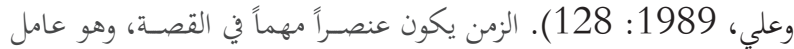
بدونه لن تنجح القصـة، مفهوم الزمن ليس في تسـسلــل اللحظات العادية

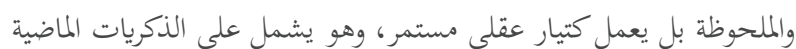

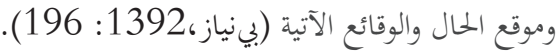

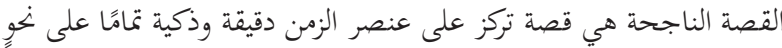
تلتزم بكل التفاصيل وحركات الخطوط الزمنية في وقت معين (الخطيب، لاتا:

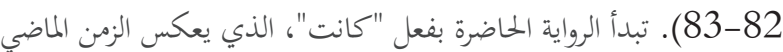

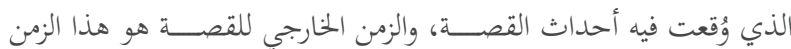

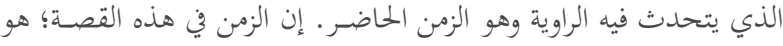
موضوعُ الكاتبة مطلعاً عليها. ولم تذهل عنها لذا فهي تحدد السـاعة أيضًا:

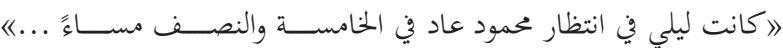
(عبدالصمد، 2015: 6) و 》امرت ساعة وهم ينتظرون) (المصدر نفسه:

النتيجة

إن بداية هذه الرواية هي تكون مزيجة من تقديم ملخصــات للقصــة وخلق أســلة ونكات غامضـــة في ذهن القارئ وتشـجيعه على قراءة تفسـيراته

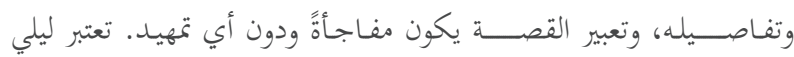
الشـخصسية الرئيسـية لهذة الرواية، التي ترتكز الرواية بأكملها حول حياتها،

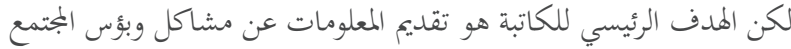

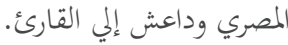
عمر يكون الشخصية الرئيسية أخرى، هو ظهر في القسم الثاني من القصة

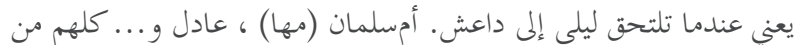
الشخصيات الثانوية في القصة.

رؤية القصـة الحالية هي بضـمير شـخص الثالث، رواها الراوية المخفية دون أي تدخل في القصــة، إن الراوية في هذا الموقف تقع في الموقع خارج عن الرقال السرد. موضوع الرواية هى قصة حياة المرأة الطليقة التي تضع الحب أساساً

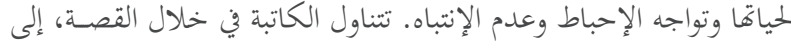

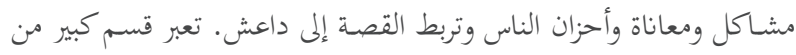

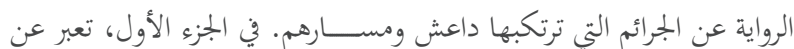
المعتقدات الاجتماعية والاقتصادية والثقافية والشعبية والجزء الثاني من الرواية هو تمثيل لأفعال وجرائم لداعش لكن في الجزء الثالث، رؤية القصـــة تكون

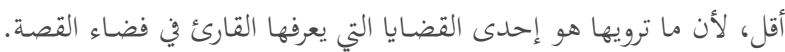

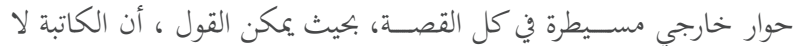
تجســم شيئاً إلا في بعض الحالات كأن تروي اقتباسـات موجودة في القصـة

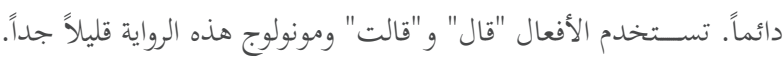

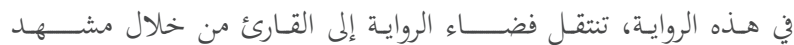

